\title{
António Ferro e a projeção atlântica de Portugal através do cinema \\ Carla Ribeiro ${ }^{1}$
}

\section{Considerações iniciais}

Em Portugal, nos anos iniciais do projeto do Estado Novo, uma questão foi intensamente debatida: deveria o Estado dirigir a atividade artística? Nesta discussão, muitos foram os que responderam afirmativamente. A nível cinematográfico, grande parte da controvérsia girou em torno da necessidade de o cinema português se construir como uma cinematografia nacional distinta de todas as outras, com temas próprios, num estilo autónomo e numa relação única com os espectadores do seu país de origem. Como um instrumento de propaganda externa do regime, o cinema assumiu um papel particularmente importante com o eclodir da Segunda Guerra Mundial, embaixador privilegiado de Portugal no estrangeiro.

Neste sentido, o presente artigo procura analisar a política externa do órgão nacional de propaganda - o Secretariado de Propaganda Nacional (SPN) dirigido por António Ferro - e as relações estabelecidas nos anos quarenta com o Brasil e a Espanha, naquilo que se entendia como uma "cruzada da lusitanidade" 2 , esclarecendo qual o papel que o cinema português desempenhou neste projeto.

\section{António Ferro, o Secretariado e o cinema}

A década de trinta iniciou-se com uma "geração de jovens furiosamente cinéfila" (Costa 1991, 38), que se ia afirmando, e aos seus ideais modernistas, através da crítica especializada nas revistas ${ }^{3}$ e na curta e média metragem, procurando desenvolver uma indústria cinematográfica portuguesa de nível europeu, que lhes permitisse afirmarem-se artisticamente.

\footnotetext{
${ }^{1}$ Instituto Politécnico do Porto, Escola Superior de Educação, InEd (Centro de Investigação e Inovação em Educação), 4200-465, Porto, Portugal.

${ }^{2}$ ANTT - Arquivo Salazar, Plano de António Ferro para uma campanha de propaganda em toda a América e no Brasil em particular, PC-12E, cx. 662, s/d, p. 25.

${ }^{3}$ Destacando-se, entre muitas outras, a Cinéfilo, o Animatógrafo, a Imagem ou a Kino, em Lisboa e, no Porto, a Movimento, o Sol Nascente, o Porto Cinematográfico, a Invicta Cine ou a Cine-revista.
} 
A criação, em 1932, da Companhia Portuguesa de Filmes Sonoros Tobis Klangfilm ${ }^{4}$ revelou-se um marco importante na odisseia cinematográfica nacional, apresentando-se como um projeto que "trabalha [...] para a criação do cinema português, feito em Portugal com elementos portugueses e para exclusiva utilidade nacional"5. Com efeito, no comunicado à imprensa, em julho, em que a Tobis apresentava as suas intenções, fundamentando-as no reconhecimento da "importância social da cinematografia sonora como meio de educação e de cultura, como instrumento de informação, documentação, propaganda e publicidade", anunciava-se um conjunto de intenções de cariz claramente nacionalista:

Move-nos, muito mais do que quaisquer considerações de carácter industrial ou comercial, um pensamento eminentemente patriótico: o de tornar possível a criação duma arte nacional que em muitos aspectos e por muitos títulos pode e deve ter uma vasta influência na vida e no progresso da Nação ${ }^{6}$.

No núcleo fundador da Tobis Klangfilm, com assento no Conselho de Produção, por nomeação do administrador-delegado da empresa, António Fonseca, encontrava-se António Ferro ${ }^{7}$.

O jovem jornalista, da primeira geração de modernistas portugueses, partilhava uma paixão pelo cinema, que se revelou logo em 1917, no seu ensaio As Grandes Trágicas do Silêncio, texto proferido no Salão Olímpia, que constituiu um pioneiro e isolado entendimento da matéria cinematográfica, uma vez que se tratou da primeira conferência sobre este assunto em Portugal $^{8}$. Este seu fascínio pela Sétima Arte tê-lo-á acompanhado ao longo dos anos e do percurso político, "embora com outros cuidados retóricos" (Torgal 2001, 164), como se verá.

Uma das personagens mais complexas, paradoxais e marcantes do Estado Novo, António Ferro viveu uma juventude artística, de pendor essencialmente literário ${ }^{9}$. A par desta sua faceta, destacou-se como jornalista no meio público nacional: em 1924 ingressou no Diário de Notícias, na sequência de uma carreira iniciada em O Século (1920), continuada no corpo redatorial do Diário de Lisboa (1921),

\footnotetext{
${ }^{4}$ Mais tarde Tobis Portuguesa e, em 1943, Companhia Portuguesa de Filmes. Localizava-se na Quinta das Conchas, ao Lumiar.

5 "Um caso sério de organização". Imagem. Lisboa, no 83, 12.6.1933, p. 6.

6 "O êxito da subscrição pública". Cinéfilo. Lisboa, n $199,11.6 .1932$, p. 3.

${ }^{7}$ Ata $n^{0} 3$ do Conselho de Administração da Companhia Portuguesa de Filmes Sonoros Tobis Klangfilm S.A.R.L., 6.6.1932.

${ }^{8}$ Neste texto, Ferro sustentava o poder onírico, ilusionista e civilizacional do animatógrafo, forma de arte autónoma, espaço de formação do gosto público e de projeção do imaginário.

${ }^{9}$ Com efeito, na primeira metade da década de 1920, Ferro dividiu-se, a nível literário, entre a poesia e a conferência, a novela e o conto, o teatro e o manifesto. Desta sua carreira destacam-se as obras Teoria da Indiferença (1920), livro de aforismos e paradoxos sobre a arte, a vida e os homens, o romance Leviana (1921), que desenhava o perfil de uma mulher mundana, urbana e moderna, o manifesto modernista Nós (1921) e a peça Mar Alto (1922).
} 
com crónicas e estudos críticos sobre literatura e teatro, e na Ilustração Portuguesa, como diretor (1922). Neste percurso, sobressaiu como entrevistador, tendo realizado um conjunto significativo de entrevistas a personalidades internacionalmente conhecidas (Torgal $2012)^{10}$.

Politicamente, Ferro sentia-se atraído pelas direitas nacionalistas e autoritárias que então despontavam no continente europeu, corporizadas por chefes dinâmicos, homens de ação, figura que encontrou no recém-nomeado Presidente do Conselho, que deu a conhecer ao público através de uma série de cinco entrevistas realizadas em finais de 1932. Terão sido estas entrevistas que o conduziram diretamente ao cargo assumido no ano seguinte, o de diretor do recém-criado Secretariado da Propaganda Nacional, então com 38 anos $^{11}$.

O ano de 1933 assumiu-se, desta forma, como o momentochave no percurso de Ferro, de conciliação da complexidade intrínseca da sua personalidade e das disparidades do seu trajeto, quando o literato talentoso e o jornalista, mesclados com um terceiro, o político, se tornaram num só, como destaca José Rebelo: “Ao transferir-se do jornalismo para a condução da propaganda do regime, António Ferro põe ao serviço da nova causa que abraça a mesma inteligência, o mesmo entusiasmo, a mesma vasta cultura e a mesma enorme capacidade de relacionação" (1998, 183).

Foi nesta linha de ação que o SPN se inseriu. O organismo foi pensado "no clima da nossa época"12, ideia presente no preâmbulo de criação do documento, nas referências feitas ao ambiente que então se vivia na Europa, aludindo à necessidade de "todos os países novos ou renascentes [em] organizar e centralizar a propaganda interna e externa da sua actividade"13. Considerando que a propaganda, nos Estados modernos, era um elemento fundamental, verificava-se ser "Portugal [...] o único país que não tinha ainda resolvido esse pro-

\footnotetext{
${ }^{10}$ Desta série de entrevistas, publicadas sob o título de Viagem à volta das Ditaduras, em 1927, destacaram-se as realizadas a Gabriel d'Annunzio, ao serviço de $O$ Século e, a partir de 1924, já no Diário de Notícias, a políticos como Mussolini, Miguel Primo de Rivera ou Mustapha Kemal, entre muitos outros.

${ }^{11}$ Criado pelo Decreto-Lei $n^{\circ} 23$ 054, de 25 de setembro de 1933, era um organismo diretamente dependente da Presidência do Conselho. Alvo de operações de cosmética em 1944, perto do final da Segunda Guerra Mundial, passou a Secretariado Nacional de Informação, Cultura Popular e Turismo (SNI) e, no período marcelista, em 1968, transformou-se em Secretaria de Estado de Informação e Turismo (SEIT).

12 "O que será o Secretariado da Propaganda Nacional”. Diário de Notícias. Lisboa, 12.10.1933, p. 1.

${ }^{13}$ Diário do Governo, I Série, no 218, decreto-lei no 23054 de 25.9.1933, art. 2º, p. 1675.
} 
blema, deixando entregues as diversas manifestações da nossa actividade ao sabor das paixões nacionais e internacionais"14.

O Secretariado deveria, por conseguinte, assumir a tarefa da divulgação dos propósitos e realizações do regime estado-novista, dirigindo e superintendendo a propaganda nacional, interna e externa. Para a consecução deste grande objetivo, tornou-se necessária a mobilização de todo o leque das atividades culturais - arte, imprensa, teatro, literatura, radiodifusão, cinema.

Imbuído de uma ânsia de renovação, Ferro adotou entusiasticamente a visão de Mussolini quanto ao poder e à função da arte no Estado: "Mussolini tem razão. A uma nova época, se essa época tem grandeza e perspectiva, deve corresponder uma nova arte" (Ferro 1949a, 22). Ferro via claramente as suas potencialidades políticas e propagandísticas: "As artes e as letras sempre foram consideradas como instrumentos indispensáveis à elevação de um povo e ao esplendor de uma época. É que a arte, a literatura [...] constituem a grande fachada de uma nacionalidade" (Ferro 1933, 8)."Expressãosíntese dos fins do SPN" (Ó 1996, 894), a "Política do Espírito" foi, pois, a ferramenta de que se serviu Ferro para atingir estes desígnios $^{15}$. Ora,

de entre todas as expressões estéticas utilizadas pelo aparelho propagandístico do Estado Novo, o cinema foi das mais privilegiadas, quer pela sua capacidade de penetração junto das massas populares como pelo alcance mais alargado da sua representação (Cunha 2010, 1).

O diretor do Secretariado, tendo compreendido desde cedo o poder do cinema como veículo de propaganda de um país ${ }^{16}$, apostava no cinema sonoro emergente no panorama nacional como forma de "o mundo nos compreend[er] a valer, definitivamente" (Ferro 1931, 129-130). Desta forma, pela "larga influência [que] exerce na reno-

\footnotetext{
${ }^{14}$ Ibidem. Com efeito, no horizonte da criação do Secretariado estiveram dois outros organismos: o Reichsministerium für Volksanfklärung und Propaganda, da Alemanha nazi, dirigido por Joseph Goebbels, e o Sottosegretariato di Stato per la Stampa e la Propaganda, da Itália de Mussolini, surgidos igualmente neste ano. Instituições estatais, o Reichsministerium e o Sottosegretariato constituíram-se como elementos de controlo dos meios de comunicação e das manifestações culturais, eliminando quaisquer formas de expressão que se pudessem opor à leitura unilinear da realidade veiculada pelos respetivos regimes. Além desta função repressiva, os dois órgãos tinham a seu cargo o vetor da propaganda, eminentemente visual em ambos os casos, apelando a meios como o cartaz e o cinema - de forte cariz emocional e simbólico - e patente em eventos públicos, como as exposições, em geral de cariz comemorativo.

${ }^{15}$ Para António Ferro, tratava-se de uma política em favor de uma cultura e de uma arte nacionalistas, do aprimoramento dos padrões estéticos da sociedade, proporcionando aos artistas "uma atmosfera em que lhes seja fácil criar" (Ferro 1935, 6), seguindo o exemplo de países como a França, a Itália, a Rússia, a Alemanha, a Inglaterra, onde "o Estado compreende a Política do Espírito e realiza-a, com largueza, protegendo, moral e materialmente, todas as iniciativas literárias e todas as iniciativas de Arte" (Ferro 1933, 226).

16 "O cinema mudo podia ter-nos popularizado, podia ter demonstrado a nossa existência, em carne e espírito” (Ferro 1931, 121).
} 
vação da alma dos povos e na projecção do seu carácter”, ao cinema nacional foi atribuída uma "difícil missão externa levando aos outros povos o conhecimento da nossa vida, do nosso carácter e do grau da nossa civilização" (Ferro 1950, 61,71). Para tal, Ferro defendia a tese de que "compete de facto aos governos orientar superiormente a cinematografia dos seus países, pela consciência do papel que ela representa na vida nacional" 17 .

Esta conceção cinematográfica não parecia sofrer contestação interna e, na revista portuense Movimento, Armando Vieira Pinto sustentava um propósito semelhante, afirmando que era necessário "produzir filmes que possam passar afoitamente as fronteiras, levando às plateias estrangeiras [...] alguma coisa que seja [...] a obra de um povo pequeno e modesto" (Pinto 1933, s/p). Na Kino, ouvia-se similarmente o eco das ideias de Ferro, pela voz de Norberto Lopes, fazendo a apologia de

um cinema estruturalmente português [...], um precioso instrumento de propaganda, se for inteligentemente aproveitado, de modo a interessar plateias internacionais [...],criando uma forte personalidade artística, que não se confunda de modo algum com a produção estrangeira (Lopes 1930, 4).

Também o diretor do hebdomadário lisboeta Animatógrafo, António Lopes Ribeiro ${ }^{18}$, reiterava estas noções, afirmando que "o Cinema não se conforma com fronteiras. Um filme precisa ser, por definição, internacional. As vantagens artísticas e comerciais dessa política são óbvias e aceites, não pela rotina, mas pela experiência" (Ribeiro 1933, 5).

E foi exatamente Lopes Ribeiro o realizador de um dos primeiros filmes portugueses concebidos com estas intenções: Gado Bravo, de 1934, resultado da criação do Bloco H. da Costa ${ }^{19}$. O Bloco ambicionava um "cinema português com classe e envergadura internacionais" ${ }^{20}$ que produzisse "filmes [...] retinta e insofismavelmente portugueses" ou seja, "concebido [s] por uma mentalidade portuguesa, filmado[s] no mesmo país, focando pedaços da nossa vida e levado[s] a cabo, exclusivamente, por capitais portugueses", películas

\footnotetext{
17 “As declarações de António Ferro”. Animatógrafo. Lisboa, n 65, 3.2.1942, p. 1.

${ }^{18}$ Com Lopes Ribeiro manteve Ferro uma longa amizade, fruto da cumplicidade de ideias e interesses, que terá começado logo em 1927, e se terá prolongado até 1956, data do falecimento do diretor do Secretariado. Ferro convidou mesmo Lopes Ribeiro para chefe da Secção de Cinema do SPN (cargo ocupado depois por Félix Ribeiro), mas este não quis abdicar da sua carreira de realizador (que manteve de 1934 a 1961). Todavia, a colaboração entre ambos durante o "período ferrista" do SPN/SNI foi regular e de relevo para o cinema nacional, com início em 1936, com A Revolução de Maio.

${ }^{19}$ Propriedade de Hamílcar da Costa, empresário português sediado em Paris, onde tinha fundado a Agência Cinematográfica H. da Costa, distribuidora de filmes.

20 “H. da Costa fala...". Movimento. Porto, nº 6, 15.9.1933, s/p.
} 
com "a unidade indispensável [para] um espectador [...] reconhecer nele[s] uma obra nacional" 21 .

Para conseguir levar a cabo uma produção contínua e industrialmente organizada, o Bloco contava com vários atores e técnicos alemães que, em virtude da subida ao poder do partido NacionalSocialista, tinham deixado a Alemanha e escolhido Portugal como destino profissional ${ }^{22}$.

O filme, em que o tema de fundo eram os toiros, era descrito pelo seu realizador como "um documento autêntico da nossa terra, de valor étnico incontestável" (Ribeiro 1983, 328), "uma obra portuguesa de cinema" (Ribeiro 1934, s/p). Após a estreia do filme, as críticas refletiram igualmente esta visão: José da Natividade Gaspar apontava-o como "uma obra-prima de fotografia, [um filme que] tem movimento, cinema, colorido; tem cor local, psicologia portuguesa", e concluía afirmando que, "desta vez, estamos perante uma dupla promessa cumprida: fez-se cinema e fez-se um filme português"23.

\section{A política atlântica}

A propaganda constituiu, pois, um dos eixos da conceção cinematográfica de Ferro: propaganda do regime, de Salazar, de Portugal. Desta forma, a cinematografia portuguesa deveria ser digna, "com uma certa elevação” (Ferro 1950, 63) e, acima de tudo, exportável.

Ora, o período da Segunda Guerra Mundial foi, entre nós, uma altura de entusiasmos. Com efeito, passaram pelo nosso país nomes bem conhecidos do panorama cinematográfico internacional, a caminho de outras paragens, e ideias e projetos foram lançados ${ }^{24}$. Por outro lado, neste período, em Portugal, tal como noutros países, existiu um cenário de rarefação da película cinematográfica, ao mesmo tempo que se verificava a estagnação da produção europeia e dificul-

\footnotetext{
21 "H. da Costa, o produtor de Gado Bravo, fala a Cinéfilo". Cinéfilo. Lisboa, nº 262, 26.8.1933, p. 26.

${ }^{22}$ Da equipa internacional de Gado Bravo destacavam-se Max Nosseck, supervisor de realização do filme; a sua esposa e atriz, Olly Gebauer; Heinrich Gärtner, fotógrafo e operador de imagens; Siegfried Arno, cómico de renome internacional; Isy Golberger, responsável pela iluminação, e Hans May, compositor.

${ }^{23}$ "Gado Bravo". Cinéfilo. Lisboa, no 313, 18.8.1934, p. 4.

${ }^{24}$ Foi o caso do reconhecido cineasta Jean Renoir, que esteve em Lisboa em finais de 1940, homenageado no Sindicato Nacional de Profissionais do Cinema, e que propôs uma União do Cinema Latino, defendendo um cinema "capaz de contrabalançar, na Europa, a escola americana [...] sob o ponto de vista puramente artístico" ("O grande realizador francês Jean Renoir está em Lisboa”. Animatógrafo. Lisboa, $\mathrm{n}^{\mathrm{o}} 4,2.12 .1940$, p. 4). A ideia de Renoir alinhava ao lado de outras, mais antigas, que sonhavam no Estoril um "Hollywood Português", um "grande centro cinematográfico internacional europeu", que teria obrigatoriamente de se encontrar num país como Portugal, que se "conserve perfeitamente neutral, perante o embate das culturas de hoje", e que possibilitasse a concorrência, em matéria de produção, com a Hollywood americana ("Portugal visto como país produtor de filmes". Cinéfilo. Lisboa, $\mathrm{n}^{\circ} 273,11.11 .1933$, p. 10).
} 
dades de distribuição dos filmes norte-americanos em território europeu $^{25}$.

Decorrente deste cenário, António Lopes Ribeiro procurou retomar o antigo projeto do Bloco $\mathrm{H}$. da Costa, referido anteriormente ${ }^{26}$ : o de uma indústria de filmes nacionais para o mercado interno mas igualmente o fomento de um mercado amplo, que abarcasse Espanha, o Brasil e toda a América Latina. Lopes Ribeiro, perante o momento singular que se vivia ${ }^{27}$, afirmava, convicto, nas páginas da sua revista:

O cinema português vive o momento mais importante da sua curta e acidentada existência. Numa hora incerta, numa Europa convulsa, num Mundo nervoso e enervado, o nosso país [...] prepara-se para marcar a sua posição definitiva na paz [...]. É preciso que o nosso Cinema seja um dos magníficos resultados dessa política sem par (Ribeiro 1941, 5$)^{28}$.

O projeto de Lopes Ribeiro harmonizava-se com o do diretor do Secretariado, de um Espaço Atlântico, englobando Portugal, o Brasil, Espanha e os países sul-americanos de língua castelhana, numa irmandade cultural ibero-americana, sustentada por uma história em comum, uma fraternidade linguística e uma unidade espiritual. Para Ferro, a arma mais poderosa e adequada à concretização desta finalidade seria o cinema. Em inícios de 1942, o diretor do Secretariado, na sequência da sua viagem pelo Brasil e América do Sul, no segundo semestre de 1941, expunha a Salazar o "Plano de uma campanha de propaganda em toda a América e no Brasil em particular”. Tratava-se de um documento extenso e pormenorizado, que se propunha repa-

\footnotetext{
${ }^{25}$ Torna-se necessário esclarecer que, no que concernia à exportação para o mercado europeu dos filmes norte-americanos, as duas exceções foram a Inglaterra e Portugal, neste último caso graças ao voo direto Lisboa-Nova Iorque.

${ }^{26}$ A procura de um mercado internacional foi, até certo ponto, um projeto acarinhado igualmente pela Invicta Filme. Fundada em novembro de 1917 por iniciativa de Alfredo Nunes de Matos, com estúdios e laboratórios instalados na Quinta da Prelada, no Porto, a Invicta Filme chegou a vender no mercado internacional produções suas, caso do filme Frei Bonifácio (1918), que foi vendido para França e para o Brasil, ou Os Fidalgos da Casa Mourisca (1920), que foi distribuído no Brasil, onde obteve um estrondoso êxito. A partir de 1923, dadas as dificuldades financeiras da empresa, verificou-se uma mudança na orientação dos filmes produzidos, procurando-se temas internacionais (e vedetas internacionais) em detrimento dos temas portugueses que tinham constituído a marca da empresa até aí. Todavia, a Invicta Filme que acabou por encerrar portas em 1930 (Pina 1986).

27 “Torna-se assim necessário e urgente aproveitar esta oportunidade única que se oferece à nossa produção, a quem a Guerra desembaraçou das suas mais perigosas concorrentes europeias" (ANTT - Arquivo Secretariado Nacional da Informação, Colocação de filmes portugueses em Espanha e no Brasil, cx. 724, 9.11.1941, p 3).

${ }^{28}$ De referir que o projeto de Lopes Ribeiro, de uma indústria cinematográfica portuguesa de produção contínua, procurava conjugar o rendimento industrial com a qualidade artística da produção cinematográfica realizada, segundo um plano previamente estudado, "duma forma permanente, metódica, organizada"; o propósito era o de manter uma equipa técnica fixa e um núcleo de atores, facilitando a reutilização de cenários e adereços (mais ou menos modificados), proporcionando desta forma uma economia de materiais e a uma maior qualidade dos filmes ("Conselho de Guerra”. Animatógrafo. Lisboa, nº 33, 23.6.1941, p. 5).
} 
rar "o abandono de qualquer programa [...] de acção espiritual ou cultural, durante tantos anos, não só no Brasil como em toda a América", assumindo como finalidade assegurar a "nossa definitiva projecção atlântica"29. Ferro apresentava uma série de medidas, atribuindo-as a diferentes ministérios e serviços que se encarregariam de as realizar: os ministérios da Educação Nacional, da Economia e dos Negócios Estrangeiros, onde se encontravam a maioria das medidas, mas igualmente o $\mathrm{SPN}^{30}$. O projeto tinha no Brasil e nos EUA as suas preocupações centrais, mas incluía um plano de aproximação com a América Latina, em particular os casos da Argentina, Uruguai, Para-

${ }^{29}$ ANTT - Arquivo Salazar, Plano de António Ferro para uma campanha de propaganda em toda a América e no Brasil em particular, PC-12E, cx. 662, s/d, p. 1.

${ }^{30} \mathrm{O}$ plano incluía um conjunto de medidas que reforçariam fortemente o papel do SPN na definição e execução da política cultural externa portuguesa, que passaria por uma captação das elites da América do Sul e por um conjunto de iniciativas que revelavam a necessidade de controlo da imagem do país, desde "orientar à distância, através de artigos e indicações, a imprensa portuguesa do Brasil e toda a imprensa portuguesa do Novo Mundo", passando por "regulamentar a ida de companhias de teatro, artistas, escritores e agrupamentos desportivos que vão ao Brasil e à América Espanhola [...], sujeitando as suas viagens ao parecer e ao visto do S.P.N., único organismo competente para conhecer as reacções dos meios estrangeiros" ou, mesmo, "evitando a publicação de certas notícias mesquinhas ou ridículas [...] que vão para o Brasil ou para outros países da América [e] nos humilham". No que dizia respeito ao Ministério dos Negócios Estrangeiros, as principais sugestões centravam-se na revisão dos corpos consulares nacionais, quer no Brasil, quer na Argentina, e na introdução, nas Legações portuguesas, de "um adido de imprensa ou delegado do S.P.N.", sugerindo Ferro que o segredo estaria "na escolha das pessoas que têm de ser o menos burocráticas possível, um bocadinho poetas ainda que poetas activos e práticos". Quanto ao papel a desempenhar pelo Ministério da Educação Nacional, Ferro sugeria um conjunto de medidas dirigidas maioritariamente às diversas comunidades portuguesas no Brasil, como a "criação de liceus portugueses no Rio e no Pará", a "organização, de acordo com o S.P.N., de cruzeiros anuais de rapazes e raparigas portuguesas das nossas colónias da América", a criação de "cursos de língua, História e literatura portuguesas" ou bolsas de estudo para "alguns brasileiros habilmente seleccionados que fiquem sempre a lembrar-se de Portugal com saudades”. No que dizia respeito ao Ministério da Economia, propunha-se a "organização duma grande campanha de propaganda dos nossos produtos não só no Brasil como em toda a América" e a conquista de turistas americanos que, "depois da guerra, não será difícil atrair, de tal forma ganhamos a reputação de país hospitaleiro, ordenado, pitoresco". De ressaltar, ainda, a procura da "defesa dos principais núcleos das colónias portuguesas" no continente americano (no Brasil, Rio de Janeiro, S. Paulo, Baía, Recife, Porto Alegre, mas também Buenos Aires, New Bedford, Nova Iorque, Oakland), assumindo o Secretariado o papel de "elemento de conciliação, e de recuperação espiritual, mantendo vivo nos emigrantes o orgulho das suas origens e elucidando-os sobre os progressos de Portugal nos últimos anos". Desta forma, propunha-se por exemplo, "acompanhar a aç̧ão dos organismos culturais das nossas colónias na América", "fazer publicações destinadas sobretudo aos filhos dos portugueses", "estimular o aparecimento [...] dum semanário português ligado encobertamente ao S.P.N. do qual receberia indicações directas" ou "propor [...] com parcimónia mas com inteligência e experiência, as condecorações que [...] parecerem indispensáveis para manter o fogo sagrado nas colónias portuguesas" (ANTT - Arquivo Salazar, Plano de António Ferro para uma campanha de propaganda em toda a América e no Brasil em particular, PC-12E, cx. 662, s/d, pp. div.). 
guai, Peru, Colômbia e México ${ }^{31}$. Relativamente à execução do plano, Ferro sugeria a instalação na América, depois da guerra, de "algumas Casas de Portugal ou simples escritórios de turismo mas sempre com uma vitrina, sempre com um chamariz" ${ }^{\prime 2}$ : em Nova Iorque (onde propunha atualizar a já existente Casa de Portugal), Chicago, Los Angeles, Rio de Janeiro, S. Paulo e Buenos Aires. Quanto a questões orçamentais, o diretor do Secretariado admitia ser um plano caro, o que se compreende se se levar em conta que, em 1941, o orçamento do SPN era de cerca de 6,4 milhões de escudos para um conjunto de dezassete funcionários (Ó 1999), sugerindo Ferro para a efetivação deste plano "uma despesa de oito ou dez mil contos anuais ${ }^{33}$, dispersa pelos orçamentos de diferentes Ministérios”, para uma duração de "dez ou quinze anos", ao fim dos quais "Portugal seria uma realidade viva na América, com todos os benefícios e vantagens consequentes de ordem moral e económica" ${ }^{34}$.

Neste documento ficava claro o papel que o cinema iria ter na materialização da projeção atlântica de Portugal, como remédio propagandístico "de acção instantânea, de consequências prontas, imediatas" (1942b, 1).

A visão de Ferro centrava-se, desde logo, no cinema americano, sustentando que "não é possível que ele continue a exercer exclusivamente a sua influência no público português" ${ }^{35}$. Na sua tentativa de contra ofensiva cinematográfica portuguesa, Ferro defendia que se deveria "tentar aproveitar a própria arma que nos combate,

\footnotetext{
${ }^{31}$ Ferro acrescentava ainda aos territórios de operacionalização da "Campanha" o Canadá, porque aí o "prestígio do Estado Novo é impressionante" e Marrocos, "porque continuamos presentes nesses nossos velhos domínios, primeiros ensaios do nosso génio conquistador e colonizador" (ANTT - Arquivo Salazar, Plano de António Ferro para uma campanha de propaganda em toda a América e no Brasil em particular, PC-12E, cx. 662, s/d, pp. 7 e 18).

${ }^{32}$ Ibidem, p. 17.

${ }^{33}$ Isto é, oito ou dez milhões de escudos.

${ }^{34}$ Ibidem, p. 26. Para que o plano tivesse viabilidade, "o ideal seria mesmo que este programa fosse executado, instalado por uma pessoa, com dois auxiliares, que lançaria os alicerces numa longa viagem que durasse o tempo necessário, ano e meio a dois anos". Para o seu sucesso, Ferro advertia Salazar que "o plano é importante e demasiado vasto para caber na rigidez dos quadros, dos regulamentos dos movimentos habituais do pessoal do Ministério dos Negócios Estrangeiros. Não basta sequer baralhar e dar de novo: é preciso criar" (Ibidem, pp. 25-26).

${ }^{35}$ Ibidem, p. 2. Com efeito, para uma certa elite intelectual e política em Portugal, o cinema estrangeiro, mas em especial o americano, pela sua força comercial, tinha um poder desnacionalizador a que era necessário resistir a todo o custo. Este ponto de vista era defendido por figuras da vida pública nacional, como Agostinho de Campos que, no Animatógrafo, discorria sobre a "invasão estrangeira do que se mete pelos olhos e pelas almas dentro, e onde não perpassa nem vislumbre do nosso carácter, nem relâmpago da nossa história, nem calor do nosso patriotismo, nem sopro do nosso génio colectivo" "Uma palestra radiofónica sobre o cinema nacional”. Animatógrafo. Lisboa, $\mathrm{n}^{\circ}$ 28, 19.5.1941, p. 5), ou Domingos Mascarenhas, que falava da "empanturradela permanente e indiscriminada de fitas estrangeiras [...] fatalmente instrumento de desagregação portuguesa" ("A invasão indesejável e dispensável”. Animatógrafo. Lisboa, no 36, 14.7.1941, p. 5).
} 
que combate a nossa própria civilização, para a combatermos, para que tal arma se desfeche contra os próprios que a apontam contra nós" ${ }^{36}$. Desta forma, no referido plano dirigido ao Presidente do Conselho, propunha-se conseguir interessar os cineastas de Hollywood no caso português ${ }^{37}$, de forma que,

se conseguíssemos que Portugal ficasse na moda, durante alguns anos, nos studios de Hollywood, ganharíamos extraordinário terreno em toda a América, no mundo, e sobretudo no Brasil que passaria a admirar-nos muito mais quanto nos sentisse em voga no país que praticamente os domina ${ }^{38}$.

Para obter esta popularização do país em terras americanas, o diretor do SPN indicava, para cônsul português em Los Angeles - a ser considerado um dos postos diplomáticos mais importantes nos EUA - a imprescindibilidade de se escolher, não um diplomata de carreira, mas "um escritor ou artista ou um simples homem do mundo com certa cultura, ponderação, habilidade, e com o sentido espectacular necessário para levar os dirigentes de Hollywood a reparar no interesse visual das nossas coisas", alguém que convivesse intimamente com os principais dirigentes e estrelas do sistema americano de cinema, de modo a conseguir que Portugal fosse "adoptado pelo cinema americano [com] consequências benéficas [...] tão grandes que chega a ser difícil calculá-las em toda a sua extensão" ${ }^{39}$. Desta forma seria projetado o "Novo Portugal" nesse espaço atlântico, como uma nação culturalmente poderosa e moderna.

\section{O Espaço Atlântico: Portugal e o Brasil}

Se até final da década de trinta, o principal cuidado do diretor do Secretariado tinha sido a propaganda pelo cinema para os portugueses - através de documentários, do jornal de atualidades, de reportagens, produzidos e financiados pelo SPN, mas também por meio da ficção ${ }^{40}$ - , a partir de $1941 / 42$, no contexto de um conflito militar mundial que deixava pouco espaço de manobra à propaganda externa nacional, afigurava-se como vital o Brasil, pelas relações históricas e pelas perspetivas de futuro.

Com efeito, o Brasil apresentava-se para Portugal como um recanto cultural privilegiado, "para mostrar aos brasileiros que Portugal tem hoje uma capacidade de realização moderna” (1942b, 2), isto é, espaço de propaganda do regime.

\footnotetext{
${ }^{36}$ ANTT - Arquivo Salazar, Plano de António Ferro para uma campanha de propaganda em toda a América e no Brasil em particular, PC-12E, cx. 662, s/d, p. 15.

${ }_{37}^{37}$ Isto é, nas suas paisagens, costumes, folclore, História, vida regional e política.

${ }^{38}$ ANTT - Arquivo Salazar, Plano de António Ferro para uma campanha de propaganda em toda a América e no Brasil em particular, PC-12E, cx. 662, s/d, pp. 15-16.

${ }^{39}$ Ibidem, p. 16.

${ }^{40}$ Foi o caso do filme A Revolução de Maio (1937), obra em que Ferro se envolveu pessoalmente, uma vez que o argumento do filme é uma coautoria: sua, com o pseudónimo de Jorge Afonso, e do realizador, António Lopes Ribeiro, com o pseudónimo de Baltasar Fernandes.
} 
Como já se viu, o interesse de António Ferro no cinema resultava de o encarar como "um dos sintomas de vitalidade - de actualidade - dos povos, um dos mais poderosos instrumentos que modernamente se encontram à disposição das Nações para vincarem a sua presença" (Ferro 1941, 5). Visto como a "arma de penetração mais poderosa do nosso tempo", Ferro considerava que "não há ofensiva tão perigosa como a das imagens, porque é a mais insinuante, a mais doce, aquela que julgamos inofensiva" ${ }^{41}$. Na realidade, no decurso do seu périplo pelo Brasil, em 1941, Ferro terá percebido que

o Cinema Português foi um dos instrumentos mais poderosos e eficazes de que dispus para o desempenho da missão de que ia incumbido [...]. Os fil$\mathrm{mes}^{42}$ que levei comigo, e que se exibiram num dos mais importantes cinemas da Cinelândia - o 'Broadway' - falaram mais directamente à alma brasileira do que o poderiam fazer centenas de discursos (1942b, 1).

Desta forma, para a tão desejada "projecção atlântica" de Portugal, Ferro propunha, entre outros meios de ação ${ }^{43}$, "introduzir o cinema português (quando este for apresentável) em bases comerciais, porque são também as melhores, para uma propaganda eficaz" ${ }^{44}$.

Assim, o fato de, na perspectiva de Ferro, o cinema se constituir como "um problema público [do qual] o Estado não pode alhearse" (1942b, 2), as facilidades que a língua em comum pareciam trazer e a consciência da superioridade da produção cinematográfica portuguesa $^{45}$ incitaram-no a procurar ativamente a entrada em força dessa indústria nacional no mercado brasileiro.

Com efeito, desde o início do projeto cinematográfico português que o mercado brasileiro era considerado essencial, pois reconhecia-se que "o mercado cinematográfico português propriamente dito [...] é muito restrito e apenas suficiente, no caso dum êxito, para amortizar, em pelo menos dois anos de exploração, as despesas de produção dum filme de custo médio"46. Assim, desde 1935 que se procuravam fomentar as relações comerciais entre os dois países, lançando-se as bases para um convénio cinematográfico luso-brasileiro entre Hamílcar da Costa, do Bloco H. da Costa, e

\footnotetext{
${ }^{41}$ ANTT - Arquivo Salazar, Plano de António Ferro para uma campanha de propaganda em toda a América e no Brasil em particular, PC-12E, cx. 662, s/d, p.14.

${ }_{42}$ No âmbito da "Semana de Filmes Portugueses" então promovida pelo SPN, do programa constavam unicamente documentários, destacando-se A Aldeia Mais Portuguesa de Portugal, a Exposição do Mundo Português ou A Manifestação a Salazar, claramente todos filmes de propaganda do regime.

${ }^{43}$ Meios como a imprensa, literatura, teatro, rádio, folclore e outras manifestações artísticas, mas também os serviços de censura.

${ }^{44}$ ANTT - Arquivo Salazar, Plano de António Ferro para uma campanha de propaganda em toda a América e no Brasil em particular, PC-12E, cx. 662, s/d, p.11.

45 "A produção cinematográfica brasileira é irregular e de má qualidade. Nos domínios técnico e artístico a produção portuguesa é-lhe muito superior" (ANTT Arquivo Secretariado Nacional da Informação, Colocação de filmes portugueses em Espanha e no Brasil, cx. 724, 9.11.1941, p. 2).

${ }^{46}$ ANTT - Arquivo Secretariado Nacional da Informação, Colocação de filmes portugueses em Espanha e no Brasil, cx. 724, 9.11.1941, p. 1.
} 
Cármen Santos, presidente da Brasil-Vita Films (Antunes e MatosCruz 1997) ${ }^{47}$. Todavia, as expetativas goraram-se, de tal forma que Leitão de Barros chegou a afirmar que "sem o mercado do Brasil, e inteiramente abandonada a produção nacional, sem uma lei que a proteja, em face da concorrência dos filmes feitos em países de grande mercado, o cinema português não viverá" (Fraga 1939, 2).

Uma solução foi então proposta por António Lopes Ribeiro, num relatório de quatro páginas datado de 9 de novembro de 1941, dirigido a Ferro, intitulado "Colocação de filmes portugueses em Espanha e no Brasil". Este documento foi elaborado no momento em que Lopes Ribeiro empreendeu as Produções $\mathrm{ALR}^{48}$, muito possivelmente como forma de conseguir um mercado mais amplo para os seus filmes, no contexto da questão da internacionalização do cinema nacional desenvolvida no ponto anterior.

No relatório, Lopes Ribeiro discorria sobre o panorama do cinema português, que considerava ter atingido "ultimamente um desenvolvimento considerável", bem como a sua necessidade de expansão, apresentando as vantagens de se conquistar comercialmente os mercados brasileiro e sul-americano, "para que a indústria nacional progrida convenientemente" ${ }^{49}$. Salientando que Portugal era o "único país produtor de filmes que não possui quaisquer medidas legais de protecção à sua própria indústria em relação à produção que importa do estrangeiro", Lopes Ribeiro compreendia que "embaraçar excessivamente a entrada de filmes estrangeiros num país que produz tão poucos traria como resultado não haver número de filmes que chegasse para manter o funcionamento dos cinemas existentes" ${ }^{\# 0}$. Desta forma, propunha como única solução para este dilema, e para a entrada em condições vantajosas dos filmes portugueses nos mercados da América do Sul, a realização de acordos com os respetivos governos - brasileiro e espanhol.

\footnotetext{
${ }^{47}$ João Antunes e José Matos-Cruz fazem referência a um primeiro e, aparentemente, único filme produzido no contexto deste convénio, de 1936: Quinze Dias de Felicidade, com realização de Humberto Mauro e supervisão de António Lopes Ribeiro, com rodagens em Sintra, Estoril, Minho e no Rio de Janeiro (1997, 49). Luís de Pina faz ainda referência à estadia em Portugal, no final dos anos vinte, de Agesilau de Araújo, produtor, e Silvino Santos, operador, portugueses radicados no Brasil, que aqui filmaram vários assuntos portugueses e apresentaram filmes sobre a Amazónia (1986, 55).

${ }^{48}$ Criada em 1941, a empresa Produções António Lopes Ribeiro prolongou o seu trabalho até 1945, numa tentativa infrutífera de produção contínua da qual resultaram apenas alguns filmes: as comédias O Pai Tirano (1941), protagonizada por Vasco Santana e Ribeirinho, e O Pátio das Cantigas (1942) e o mítico Aniki-Bobó (1942), de Manoel de Oliveira.

${ }^{49}$ ANTT - Arquivo Secretariado Nacional da Informação, Colocação de filmes portugueses em Espanha e no Brasil, cx. 724, 9.11.1941, pp.1-2.

${ }^{50}$ Ibidem, p. 4.
} 
Lopes Ribeiro tinha noção de que o cinema português no Brasil era bem recebido, em particular pelos emigrados portugueses ${ }^{51}$, mas tinha igualmente consciência das difíceis condições de exibição no Brasil dos filmes portugueses: "Ou vendidos a fixo, por baixo preço, ou explorados directamente por concessionários portugueses, que têm que lutar contra a organização defensiva dos exibidores brasileiros, constituídos num autêntico trust" ${ }^{\text {22 }}$.

Desta forma, procurando, em simultâneo, escapar a esta situação de trusts e satisfazer "a colónia portuguesa do Rio, público com que os nossos filmes contam principalmente e que sempre os recebe com alvoroço" ${ }^{53}$, propunha a compra ou aluguer de um cinema no Rio de Janeiro, onde os filmes portugueses passassem em condições favoráveis. Sugeria ainda "medidas de facilitação recíproca", como diminuir ou anular os direitos de exportação/importação de filmes entre os dois países ou, considerando que "em Portugal, os cinemas pagam menos impostos durante a exibição de filmes portugueses, poder-se-iam equiparar os filmes brasileiros aos filmes portugueses [...], obtendo igual vantagem no Brasil” ${ }^{\prime 4}$.

Lopes Ribeiro terminava esta secção do relatório referindo que, face à viagem de Ferro ao Brasil e à existência, neste país, de "um organismo oficial que centraliza e coordena a distribuição de

\footnotetext{
${ }^{51}$ Foi o caso dos filmes que, "seguindo a trajectória da memória da colónia, recordam a terra natal e se coadunam com os novos gostos desenvolvidos pelos emigrantes em terras brasileiras" (Paulo 2001, 121). As comédias de costumes parecem ter sido particularmente do agrado deste público, caso de $A$ Canção de Lisboa (1933), O Trevo de Quatro Folhas (1936), O Costa do Castelo (1943), O Leão da Estrela (1947), mas igualmente dramas com fundo musical, como Bocage (1936), Capas Negras e Fado, História de uma Cantadeira (ambos de 1947). Todavia, o campeão de reposições e de bilheteira no Brasil terá sido A Severa (1931), que obteve do público da colónia nacional "uma fidelidade constante num período de mais de vinte anos" (Paulo 2001, 124), reposto mais de uma dezena de vezes, de 1933 até finais da década de cinquenta.

${ }^{52}$ ANTT - Arquivo Secretariado Nacional da Informação, Colocação de filmes portugueses em Espanha e no Brasil, cx. 724, 9.11.1941, p. 2. Esta situação não escapou, aliás, à análise das revistas portuguesas da especialidade, que se referiam à "mesquinhice de certos interesses, debatendo-se [o filme português], tal qual o filme brasileiro, com a ambição desmedida dos exibidores do Brasil. Dois ou três magnates, detentores de grandes circuitos de cinema, fazem exigências incomportáveis, tornando impossível a movimentação satisfatória das nossas fitas. Evidentemente que a sua única mira é comprar tais produções. 'Interessa-lhes mais' serem eles os seus únicos detentores no Brasil, adquirindo os respectivos direitos por quantias irrisórias"("Português sem calão". Animatógrafo. Lisboa, no 40, 11.8.1941, p. 5). Heloísa Paulo refere que neste período dos anos quarenta foi inclusive criada a Pascoal Segreto, firma de empresários portugueses radicados no Rio de Janeiro, destinada unicamente à distribuição de filmes feitos em Portugal, projeto que parece não ter resultado, acabando por sobreviver graças à reposição de filmes consagrados $(2001,120)$.

${ }^{53}$ ANTT - Arquivo Secretariado Nacional da Informação, Colocação de filmes portugueses em Espanha e no Brasil, cx. 724, 9.11.1941, p. 2.

${ }^{54}$ Ibidem.
} 
filmes, com o qual seria possível estabelecer [...] um acordo" ${ }^{\text {, }}$, restava esperar pelo regresso do diretor do Secretariado para se encontrar uma solução viável.

E, com efeito, quando Ferro regressou da sua viagem ao Brasil, em inícios de 1942, trazia na mala o Acordo Cultural Luso-Brasileiro, assinado a 4 de setembro de 1941, entre o SPN e o Departamento de Imprensa e Propaganda (DIP) brasileiro, dirigido por Lourival Fontes ${ }^{56}$. Este acordo constituía a formulação concreta dos ideais de Ferro, que acreditava na "necessidade e mérito de dar a todos os elementos dispersos de fraternidade e inteligência nos dois povos um sentido, uma fórmula, uma significação [para] duas Pátrias, nascidas do mesmo coração" (1942c, 1).

\section{Assim, no artigo $2^{\circ}$, alínea $\mathrm{K}$, fazia-se referência à}

troca de actualidades cinematográficas, a exibição destas nos cinemas do Brasil e Portugal, e o estudo da eventual realização de filmes de grande metragem, de interesse histórico ou cultural para os dois países, mediante a colaboração de artistas e técnicos brasileiros e portugueses (Ferro 1949b, 112).

Porém, se por um lado se procurava a intensificação da "produção e troca de actualidades" entre os dois países, deixava-se a questão, bem mais relevante, da "realização de filmes em conjunto" para abordar "depois de regulados os problemas internos da nossa produção cinematográfica” (1942b, 2).

E assim, o projeto cinematográfico entre Portugal e o Brasil, assente no Acordo Cultural de 1941, parece quase não ter saído do papel em que foi assinado. A concretização do acordo resumiu-se ao envio de alguns filmes portugueses para o Brasil, passados nas sema-

\footnotetext{
${ }^{55}$ Ibidem.

${ }^{56}$ O DIP, Departamento de Imprensa e Propaganda foi criado através do decreto presidencial $\mathrm{n}^{\circ} 1915$, de 27 de dezembro de 1939. Na verdade, a sua origem remontava a um período anterior: em 1931 foi criado o Departamento Oficial de Publicidade (DOP), substituído, em 1934, pelo Departamento de Propaganda e Difusão Cultural (DPDC). Já no Estado Novo, no início de 1938, o DPDC transformou-se no Departamento Nacional de Propaganda (DNP) que, finalmente, deu lugar ao DIP. Muito semelhante nos seus fins e meios de ação ao congénere português (o Secretariado de Propaganda Nacional), subordinado, também ele, à Presidência da República, tinha como objetivos coordenar a propaganda nacional, auxiliar os ministérios com informações, organizar os serviços de turismo, controlar os meios de comunicação e as atividades recreativas e desportivas, estimular a produção de filmes educativos, organizar e patrocinar comemorações e festas cívicas e dirigir o programa de radiodifusão do governo. Contando com a colaboração de nomes expressivos da intelectualidade brasileira, este organismo assumiu um papel fundamental na elaboração e realização do projeto cultural do Estado Novo e na construção da imagem do presidente Getúlio Vargas. A sua direção foi entregue, até 1942, a Lourival Fontes, jornalista e intelectual partidário de Vargas, que já dirigira o DPDC e o DNP. Os seus sucessores foram o major Coelho dos Reis, de agosto de 1942 até julho de 1943, e o capitão Amílcar Dutra de Menezes, que atuou até à extinção do DIP, em 1945, com a deposição de Getúlio Vargas Cf. http://cpdoc.fgv.br/producao/dossies/AEraVargas1/anos37-

45/EducacaoCulturaPropaganda/DIP.
} 
nas dedicadas ao cinema português, que funcionaram essencialmente como instrumentos de legitimação e difusão ideológica do regime salazarista entre a colónia nacional residente nesse país ${ }^{57}$.

Para este insucesso, terão contribuído uma plêiade de factores. Desde logo, a falta de boas condições técnicas de exibição, em especial a nível da qualidade sonora das cópias, por vezes inaudíveis, e a distância idiomática entre o português falado nos dois países, dificultando a compreensão do público não emigrante, chegando-se mesmo a pugnar, no Brasil, pela necessidade de legendas (Paulo 2001). Politicamente, pode-se incluir na lista de razões os ataques da oposição portuguesa, no Brasil, ao regime salazarista, realizando, por exemplo, manifestações diante dos cinemas que exibiam os documentários portugueses, ao domingo, bem como a entrada do Brasil na Segunda Guerra Mundial, ao lado dos Aliados, em 1942, acontecimento que marcou o início de um progressivo afastamento em relação às potências do Eixo e a regimes como o de Salazar e, em 1945, o fim do Estado Novo brasileiro e do governo de Getúlio Vargas, o que resultou no fato de as relações culturais luso-brasileiras estabelecidas, e os planos para uma aproximação cinematográfica entre os dois países, terem caído por terra.

\section{O Espaço Atlântico: Portugal e a Espanha}

No "Plano de uma campanha de propaganda..." anteriormente apresentado, Ferro não esqueceu a importância de Espanha na política externa portuguesa. Tendo em consideração, como lhe era apontado por Lopes Ribeiro, que "embora em Espanha se produzam, actualmente, mais de 100 filmes por ano, eles ainda são insuficientes para abastecer um mercado de 2.000 cinemas" ${ }^{\text {"58 }}$, Ferro procurou um possível e vantajoso acordo com Espanha, "através de um intercâmbio inteligentemente estudado" ${ }^{29}$.

De salientar que os cineastas portugueses já tinham iniciado, em 1936, um movimento ibérico de coprodução cinematográfica com o país vizinho, através de Leitão de Barros e do seu Bocage com

\footnotetext{
${ }^{57}$ Todavia, a partir da década de cinquenta, as exigências deste público tornaram a frequência das salas de cinema, nas "Semanas do Filme Português" (iniciativa que contava com o apoio da representação consular), cada vez menos atrativa, habituados como estavam às modernas técnicas do cinema norte-americano que aí chegava facilmente, dominando as salas de cinema; a este fator somou-se o aumento da produção e da popularidade do cinema brasileiro, que "ganha novo fôlego nesta época com comédias e musicais” (Paulo 2001, 132). O cinema português que então chegava ao Brasil centrava-se na reposição das comédias dos anos trinta e quarenta, sucessos garantidos, e na exibição de documentários.

58 ANTT - Arquivo Secretariado Nacional da Informação, Colocação de filmes portugueses em Espanha e no Brasil, cx. 724, 9.11.1941, p. 3.

59 ANTT - Arquivo Salazar, Plano de António Ferro para uma campanha de propaganda em toda a América e no Brasil em particular, PC-12E, cx. 662, s/d, p. 17.
} 
versão espanhola (Las Três Gracias) ${ }^{60}$. Pode inclusive recuar-se mais, até 1934, quando a imprensa especializada noticiava a constituição de um consórcio luso-espanhol para produção de filmes, entre o Bloco H. da Costa e a Ibérica Filmes, de Barcelona ${ }^{61}$, iniciativa que se parecia enquadrar na defesa que então se fazia, no meio cinematográfico nacional, da permuta de filmes portugueses e espanhóis ${ }^{62}$. Por outro lado, há que registar as ligações do cineasta Arthur Duarte ao cinema espanhol, contratado como assistente geral de produção da empresa Ibérica Filmes até ao início da guerra civil, e do próprio António Lopes Ribeiro, que vai buscar a Espanha os técnicos que com ele colaboraram em Gado Bravo ${ }^{63}$.

Todavia, foi só nos inícios dos anos quarenta, em plena Segunda Guerra Mundial que, no seguimento das iniciativas particulares, se terá verificado a procura de um acordo político formal de coprodução cinematográfica entre as duas nações ibéricas. Deste modo, em janeiro de 1941, Manuel Garcia Viñolas, o responsável pelo Departamento Nacional de Cinematografia espanhola ${ }^{64}$, deslocou-se a

\footnotetext{
${ }^{60}$ Este cineasta, já em 1930, no período de introdução do cinema sonoro, advogava um cinema nacional com versões espanholas, procurando dessa forma atingir "todos os povos de língua portuguesa e espanhola, ou seja, Portugal, Brasil, Espanha, América Latina e as respectivas colónias" ("O que vai fazer Leitão de Barros”. Kino. Lisboa, $\mathrm{n}^{\circ}$ 10, 3.7.1930, p. 4). Relativamente a Bocage, filme realizado para a produtora espanhola Hispano-Português e para a portuguesa Sociedade Universal de Superfilmes, de referir que o ajudante de realização foi Arthur Duarte. As duas versões foram filmadas nos estúdios da Tobis, em Lisboa. A versão portuguesa teve a sua estreia a 1 de dezembro de 1936 mas em Espanha o filme só será estreado a 4 de março de 1940.Uma das finalidades das duas versões foi a possibilidade de exportação para o mercado da América Latina; desta forma, é de salientar que o filme alcançou um enorme êxito no Brasil (estreou-se em meados de 1937) e na Argentina (onde estreou em novembro de 1938).

${ }^{61}$ Cf. Cinéfilo. Lisboa, $\mathrm{n}^{\mathrm{o}} 314,25.8 .1934$.

${ }^{62}$ Com efeito, defendia-se um projeto de "intercâmbio de filmes [que] poderia mesmo vir a ser a origem de trabalhos de grande envergadura realizados com duas versões: a portuguesa e a espanhola, que alastraria pela América Central e do Sul, e que iriam percorrer os 'écrans' da Europa, da África e da Ásia” (“O cinema espanhol”. Imagem. Lisboa, $\mathrm{n}^{\circ} 107,1.12 .1934$, p. 7).Todavia, a primeira coprodução de que se tem conhecimento remonta ao ano de 1924, quando o realizador português Reinaldo Ferreira dirigiu em Espanha o filme El Botones del Ritz (O Groom do Ritz). $\mathrm{O}$ filme foi inteiramente filmado em Lisboa, embora fosse protagonizado apenas por atores espanhóis (Pina 1986).

${ }^{63}$ Os alemães Nosseck, Gärtner, Goldberg, e o espanhol Bernaldez que, tendo sido assistente técnico de Lopes Ribeiro em A Revolução de Maio e diretor de som em Gado Bravo, dirigiu após a guerra civil um estúdio em Chamartin de la Rosa, a norte de Madrid.

${ }^{64}$ Em 1938, é criado pelo Governo de Burgos o Departamento Nacional de Cinematografia (DNC), dependente do Ministério do Interior. No ano seguinte, com o fim da Guerra Civil espanhola, verificava-se o aparecimento da Delegación Nacional de Prensa y Propaganda, dirigida por Ramón Serrano Suñer, tendo o Departamento de Cinematografia ficado adstrito a este organismo, por sua vez integrado no Ministério do Interior. A Delegación Nacional de Prensa y Propaganda era ainda formada por uma Direção Geral de Propaganda, uma Direção Geral de Imprensa e um Serviço de Radiodifusão. O DNC foi dirigido desde 1938 por Manuel Augusto Garcia Viñolas, poeta e jornalista, fundador e diretor da revista Primer Plano (1940) e do
} 
Lisboa $^{65}$ onde se encontrou com António Ferro, ficando assente "a colaboração efectiva em filmes de interesses comum aos dois países" ${ }^{\circ 6}$.

Para que da ideia nascesse uma realidade, Ferro contava com a ajuda preciosa de Lopes Ribeiro. O cineasta, nas páginas do seu Animatógrafo, ia fazendo campanha por um

cinema ibérico, [uma] régia empresa cinematográfica, a que levam os seus entusiasmos e os seus desvelos, com inquietações e ambições irmãs, Espanha e Portugal [...], para que surja um Cinema suficiente, forte e digno, capaz de se bastar em qualidade e quantidade, em técnica e em capacidade mercantil [...], para erguer diante da América do Norte um conjunto de possibilidades novas (1942a, 1).

Homem de ação, Lopes Ribeiro propôs ainda medidas concretas para uma colaboração profícua entre os dois países ibéricos, no relatório de novembro de 1941 anteriormente apresentado. Partindo da noção que, "quanto à qualidade, a produção espanhola é manifestamente inferior à produção cinematográfica portuguesa", o realizador pretendia aproveitar, por um lado, a abertura demonstrada por Garcia Viñolas, quando da sua vinda a Lisboa, de "um acordo entre Portugal e Espanha para a exploração nos dois mercados da respectiva produção nacional" e, por outro lado, o fato de "o mercado espanhol [se] encontra[r] praticamente fechado à [...] produção americana" e a toda a produção estrangeira em geral, devido aos impostos proibitivos para a importação de filmes ${ }^{67}$.

Deste modo, propunha-se viajar até Madrid para auscultar o meio cinematográfico, "acção que seria extremamente facilitada se levasse filmes para mostrar”, elaborando depois um relatório para o SPN, para que dessas conclusões "pudesse beneficiar a produção cinematográfica portuguesa"68. Para a concretização de um efetivo intercâmbio luso-espanhol, Lopes Ribeiro advogava que seriam necessárias as seguintes concessões: uma "taxa especial para a licença de entrada dos filmes portugueses em Espanha, compensada com diminuição de impostos aduaneiros e de exibição dos filmes espanhóis em Portugal”, a necessidade de dobragem em língua castelhana

Círculo Cinematográfico Espanhol (1941). Mais tarde, na década de cinquenta, Garcia Viñolas foi Agregado Cultural de Espanha no Brasil e em Portugal (Folgar de la Calle 2006 e Minguet i Batllori 2000).

${ }^{65}$ Garcia Viñolas foi recebido à chegada por Lopes Ribeiro e Fernando Fragoso, correspondente em Portugal do Primer Plano e jornalista do Cinéfilo.

66 "António Ferro regressa do Brasil disposto a defender os direitos do cinema português”. Animatógrafo. Lisboa, nº 62, 13.1.1942, p. 1.

${ }^{67}$ ANTT - Arquivo Secretariado Nacional da Informação, Colocação de filmes portugueses em Espanha e no Brasil, cx. 724, 9.11.1941, p. 3. O cineasta descrevia desta forma a situação que então se vivia no país vizinho: "Cada filme é obrigado a pagar uma 'licença de entrada' de 25, 50 ou 75.000 pesetas [...], pesados direitos alfandegários, dobragem obrigatória, e que custa cerca de 45.000 pesetas. Com as cópias e material de reclamo indispensáveis, cada filme estrangeiro paga portanto, para ser exibido em Espanha, de 100 a 150.000 pesetas" (Ibidem, pp. 3 e 4).

${ }^{68}$ Ibidem, p. 3. 
das películas portuguesas, de forma a atingir não apenas o mercado espanhol mas, acima de tudo, a América espanhola, onde "os filmes falados em espanhol gozam de um tratamento especial", e a "distribuição em Portugal dos filmes espanhóis em condições vantajosas para ambas as partes, em troca da distribuição em Espanha de filmes portugueses"69. Lopes Ribeiro confiava que um acordo com Espanha e o Brasil "traria atrás de si um mercado tão vasto e compensador, que desenvolver-se-ia automaticamente a nossa indústria de filmes", uma vez que previa um espaço de colocação para os filmes nacionais "de 145 milhões de indivíduos, pois tantos são os que falam português (55 milhões) e espanhol (90 milhões)"70.

Em finais de 1943, começava desta forma uma colaboração cinematográfica contínua, sucedendo-se as coproduções: o húngaro Ladislau Vadja, radicado em Espanha, assinava a realização de O Diabo São Elas (1945), Três Espelhos (1947) e Viela - Rua Sem Sol (1947), enquanto Arthur Duarte filmava em Madrid Es Peligroso Asomarse el Exterior (1946), El Huesped del Cuarto Trece (1947) e Fuego $(1949)^{\mathbf{7 1}}$. Desta colaboração luso-espanhola resultaram ainda os filmes Madalena, Zero em Comportamento (1944), de F.M. Topel, A Mantilha de Beatriz (1946), de Eduardo Maroto, Mañana como hoy (1947), de Mariano Pombo, Rainha Santa (1947) ${ }^{72}$ ou Senhora de Fátima (1951), de Rafael Gil. Nas palavras de Leitão de Barros, em entrevista dada ao Diário Popular em 11 de dezembro de 1944: "Tanto Portugal como a Espanha ganham com a iniciativa de fazer filmes destinados aos dois mercados de antemão garantidos" (Ribeiro 1983, $446)^{73}$.

Todavia, apesar da produção, neste sistema, de vários filmes, poucos mereceram o apoio estatal, exceção feita a Inês de Castro (1945), de Leitão de Barros, uma coprodução apoiada por Ferro, através do SPN, e por Garcia Viñolas, pelo Departamento Nacional de

\footnotetext{
${ }^{69}$ Ibidem, pp. 3 e 4.

${ }^{70}$ Ibidem, p. 4.

${ }^{71}$ De referir ainda as obras portuguesas de realizadores espanhóis experimentados, mas de segunda categoria, como Cais do Sodré (1946) e Os Vizinhos do Rés do Chão (1947), de Alexandre Perla, Não há Rapazes Maus (1948) de Eduardo Maroto e Sol e Toiros (1949) de José Buchs.

${ }^{72}$ Rainha Santa foi, aliás, o primeiro filme das Produções Aníbal Contreiras, que foi também autor do argumento e responsável pela versão portuguesa. Como era costume nas coproduções com Espanha, o filme contava no elenco com artistas de vários países: do lado português, António Vilar (no papel do Rei D. Dinis), Virgílio Teixeira (no papel de D. Afonso Sanches), Barreto Poeira (no papel de escudeiro do rei) e ainda Julieta Castelo (como aia da rainha). O filme foi uma autêntica super produção para a época, tendo ganho, no país vizinho, o prémio de melhor realizador, atribuído pelo Círculo de Escritores Cinematográficos, e ainda o terceiro prémio de melhor filme atribuído pelo Sindicato Nacional del Espectáculo. Cf. http://www.cinemaportugues.ubi.pt/bd/info/1895.

${ }^{73} \mathrm{O}$ intercâmbio português também se cifrou na passagem para Espanha de diversos atores portugueses, como Milú, António Vilar, Virgílio Teixeira ou Raul de Carvalho.
} 
Cinematografia Espanhola ${ }^{\mathbf{7 4}}$. Para Maria do Carmo Piçarra, este era o filme através do qual Ferro e Viñolas "esperavam que a então apregoada Irmandade Ibérica viesse a traduzir-se num acordo político de co-produção cinematográfica" (2006, 98). Contudo, apesar da estreia de gala, no S. Luís, com a presença do Presidente da República, e de em Espanha ter sido considerado de interesse nacional e ter ganho o primeiro prémio no concurso Melhores Filmes Estreados em Espanha, a verdade é que o filme não produziu o efeito político esperado, de criação de um regime concertado de coproduções, e a cooperação continuou, mas em moldes puramente particulares.

Esta colaboração, que trouxe uma certa atividade aos estúdios portugueses, terá terminado no início da década de cinquenta, fruto de um conjunto de circunstâncias e razões: por um lado, em Portugal, estas coproduções parecem ter tido carreiras comerciais discretas e a própria indústria nacional deixou de ter dinheiro, apesar da Lei $\mathrm{n}^{\circ} 2$ 027 , de $1948^{75}$; por outro lado, a Espanha, "à medida que ia entrando noutros mercados, [desinteressou-se] dessas versões duplas para Portugal" (Costa 1996, 51).

Assim, da projetada Irmandade Ibérica cinematográfica, pouco parece ter sido materializado: a obra Inês de Castro, coprodução entre o SPN e o Departamento Nacional de Cinematografia espanhol, foi o único filme a merecer o apoio estatal, e um dos projetos mais ambiciosos, um filme conjunto sobre Fernão de Magalhães e o Tratado de Tordesilhas, nunca se terá concretizado.

\section{Considerações Finais}

Para a formação e sustentação ideológica do Estado Novo, contribuíram quer os instrumentos repressivos, quer os mecanismos de reprodução ideológica. Neste último caso, a cultura em geral, e as diversificadas manifestações culturais em particular, desempenharam um papel crucial.

António Ferro, diretor do Secretariado de Propaganda Nacional, teve "desde sempre a noção de que a cultura era também uma arma política, pelo que a sua presença à frente do SPN/SNI o tornaria um excelente 'intelectual orgânico' ao serviço do Estado Novo” (Tor-

\footnotetext{
${ }^{74}$ Em algumas bases de dados, António Ferro e Garcia Viñolas aparecem referenciados como autores do argumento e, noutras, Garcia Viñola é creditado como corealizador Cf. http://www.cinemaportugues.ubi.pt/bd/info/2897.

${ }^{75}$ A lei de Protecção ao Cinema Nacional, de 1948, tinha como objetivos proteger o cinema português e promover a produção fílmica, pela criação do Fundo de Cinema Nacional (FCN), sob a administração do SNI, apoiado por um órgão de consulta, o Conselho do Cinema, dominado por representantes do Governo. Ora, as quantias apuradas para o Fundo do Cinema eram notoriamente escassas, por um lado e, por outro, a legislação condicionava as verbas do Fundo a obras representativas do espírito português, tornando a produção fílmica nacional num projeto político mais do que cinematográfico.
} 
gal 2012, 82 $)^{76}$. Desta forma, o organismo nacional de propaganda teve uma "acção significativa, procurando dar um 'sentido nacional' a toda a cultura, entendendo por 'nacional' o que era a ideologia do Estado Novo" (Torgal 2012, 202).

Neste contexto, com o eclodir da Segunda Guerra Mundial, as relações externas de Portugal em matéria de propaganda, cultivadas por António Ferro desde 1933 com o centro cultural europeu, a França, ficaram em suspenso, dada a participação deste país no conflito.

Assumida a neutralidade como orientação fundamental da política externa portuguesa, a ação espiritual e cultural que o diretor do Secretariado de Propaganda Nacional procurava desenvolver para "o justo conhecimento da nossa terra, do nosso povo e da nossa história" virava-se para o Brasil e a Espanha, contando para tal com "uma actividade que tem [...] grandes possibilidades de servir o prestígio de Portugal" "77: o cinema. Um cinema dotado de um espírito nacional, personalizado, um cinema que refletisse "a nossa personalidade, a nossa moral e até a nossa estética de vida” (Ferro 1950, 46).

Como se viu, no Brasil, a ação cinematográfica do SPN procurou atingir diferentes públicos, com complementares objetivos. Assim, por um lado, procurou reforçar e fortalecer a identidade nacional face ao que então ocorria na Europa e, através do Brasil, amplificar a voz de Portugal no mundo; por outro, tratou-se de um esforço para produzir um maior conhecimento da realidade portuguesa entre os brasileiros, procurando-se o fortalecimento das afinidades entre as duas comunidades; finalmente, ao dirigir-se à colónia lusa no Brasil, o cinema foi usado como forma de combater o que se percecionava como desnacionalização, mantendo vivo o sentimento português de uma comunidade de emigrantes há muito longe da pátria e, em simultâneo, funcionando como fator de propaganda e de legitimação do regime salazarista junto destes portugueses.

Em Espanha, o cinema assumiu na teoria um papel importante na aproximação peninsular empreendida nos anos de guerra, elemento indispensável ao reafirmar de uma "unidade espiritual" hispanoportuguesa, sustentada em fatores como "fraternidade, vizinhança, afinidades linguísticas, glórias e preocupações comuns, a mesma religião, laços de cultura, idêntica vocação universalista" ${ }^{\text {" }}$.

Nos dois casos, como se viu, os projetos cinematográficos de cooperação delineados por Ferro foram desencadeados pelo conflito mundial, tendo obtido resultados muito aquém das expectativas do

\footnotetext{
${ }^{76} \mathrm{O}$ conceito de intelectual orgânico defendido por Luís Reis Torgal refere-se a "intelectuais que estão fundamentalmente ao serviço de um movimento organizado, de um partido ou de um regime" (Torgal 2012, 75).

${ }^{77}$ Diário do Governo, I Série, no 295 , decreto-lei no 36062 de 27.12.1946, p. 1316.

78 “O Bloco Peninsular". Ocidente, Revista Portuguesa de Cultura. Lisboa, ${ }^{\circ}$ 59, março de 1943, p. 252.
} 
diretor do Secretariado. Que razões se podem apresentar para este insucesso?

O "Plano de uma campanha de propaganda em toda a América e no Brasil em particular" idealizado por Ferro era, claramente, um projeto grandioso, de tal forma que o próprio Ferro admitia que pudesse parecer, a olhos estranhos, um plano "dispendioso, pueril, inútil", de "incomensurável ambição, de estranha megalomania"79. Todavia, pedia para ele "a confiança absoluta do seu chefe", pelos "benefícios e vantagens consequentes de ordem moral e económica", pelo "alargamento [...] das nossas fronteiras espirituais" $"$. Mas o projecto nunca terá passado disso mesmo, não se conhecendo resposta de Salazar. Muito provavelmente, o Presidente do Conselho, no seu rigor normal com as despesas do Estado, tê-lo-á considerado demasiado caro.

Possivelmente ainda mais importante para a desistência deste projeto terá sido o desenvolvimento da Segunda Guerra Mundial, com a vitória final dos Aliados, resultando, em Portugal, num conjunto de mudanças, mais estéticas do que reais ${ }^{81}$. Uma delas foi no SPN, que em 1944 passou a SNI - Secretariado Nacional de Informação, Cultura Popular e Turismo ${ }^{82}$. No novo Secretariado, verificava-se de forma clara o acentuar de uma faceta mais coercitiva do organismo, concentrado agora em tarefas mais internas do que externas, em funções mais repressivas do que de propaganda. Com o afastamento de Ferro do Secretariado, em 1949, os diretores que se lhe seguiram conduziram ao esmorecimento da sua "Política do Espírito", podendo afirmar-se que, após a sua saída, "a intervenção do SNI esbate-se, os projectos são menos aparatosos ou ambiciosos, a estratégia de cober-

\footnotetext{
79 ANTT - Arquivo Salazar, Plano de António Ferro para uma campanha de propaganda em toda a América e no Brasil em particular, PC-12E, cx. 662, s/d, p. 26.

${ }^{80}$ Ibidem.

${ }^{81}$ Para Fernando Rosas, mantendo os velhos dispositivos institucionais, impôs-se uma "contenção ideológica, [uma] nacionalização dos propósitos, [um] disciplinamento e burocratização das vontades e modos de agir” (2001, 1049).

${ }^{82}$ O Secretariado, com um organigrama bem mais complexo, apresentava agora uma divisão em quatro repartições, encarregadas dos serviços relativos à Administração Central, Informação, Cultura Popular e Turismo. À Repartição de Informação correspondiam quatro secções: estudo e difusão de informações, imprensa portuguesa, imprensa estrangeira e intercâmbio luso-brasileiro; dela dependiam a Biblioteca, o Arquivo Fotográfico e os Postos de Radiodifusão. A Repartição de Cultura Popular agrupava, em três departamentos, as vertentes de exposições e realizações diversas, cinema e publicações, etnografia, teatro e música. Por fim, a Repartição de Turismo incluía os sectores de turismo geral, local e indústria hoteleira, ampliando a ação anteriormente desenvolvida pelo SPN a este nível. O novo organismo assegurava ainda o controlo sobre a informação e a imprensa, com as seguintes funções: o registo e licença para jornalistas e agências noticiosas, a censura prévia, o controlo da radiodifusão e a execução das antigas atribuições da Inspeção dos Espetáculos, o que lhe permitia centralizar a fiscalização e o fornecimento de registos, licenças e vistos para toda e qualquer manifestamanifestação artística ou casa de espetáculo aberta ao público.
} 
tura menos globalizante ou sistemática [...], os públicos mais delimitados e compartimentados" (Melo 2001, 211).

Em termos cinematográficos, o fim da Segunda Guerra Mundial, coincidente com o declinar do projeto de internacionalização de Lopes Ribeiro, marcou tempos difíceis para o cinema português, que se prolongaram pela restante década de quarenta e primeira metade dos anos cinquenta. O próprio interesse do público pelo cinema nacional esmoreceu, vítima de uma filmografia onde a dificuldade de criação de enredos expressamente feitos para cinema era remediada com adaptações sucessivas de êxitos do teatro ou da literatura.

Ora, o cinema nacional do período imediatamente posterior ao fim do conflito mundial não tinha poder competitivo, no Brasil, face à concorrência norte-americana, tecnicamente mais evoluída, como se viu, e com uma produção, em termos quantitativos, esmagadora. Quanto à América Latina, embora Ferro acreditasse que "todos os acordos que se estabeleçam com o cinema espanhol terão a sua influência benéfica na América espanhola pela facilidade de projecção dos nossos filmes [...] e pelo próprio reflexo do nosso espírito em [...] grandes filmes de colaboração ibérica" ${ }^{83}$, a verdade é que este mercado estaria ocupado já pelas versões em castelhano de filmes de Hollywood.

Todavia, as razões aqui aventadas para o insucesso dos projetos cinematográficos de António Ferro no Brasil e na América Latina, via Espanha, explicam apenas em parte a questão.

Desta forma, seria importante compreender a estratégia franquista para o Brasil e para a América Latina, a nível cinematográfico, mas também o pensamento de Vargas relativamente à colocação da filmografia brasileira em Portugal e, até, em Espanha. Por outro lado, seria essencial revelar o papel dos opositores salazaristas no Brasil para o insucesso do plano de Ferro. A resposta a este conjunto de interrogações que aqui se lançam será, pois, particularmente valiosa para o estudo desta temática, esperando-se que possam trazer maiores esclarecimentos quanto a este assunto.

\section{BIBLIOGRAFIA}

s.a. 1942a. "António Ferro regressa do Brasil disposto a defender os direitos do cinema português”. Animatógrafo, 62, 13 de janeiro.

\footnotetext{
${ }^{83}$ ANTT - Arquivo Salazar, Plano de António Ferro para uma campanha de propaganda em toda a América e no Brasil em particular, PC-12E, cx. 662, s/d, p. 17.
} 
s.a. 1942b."As declarações de António Ferro”. Animatógrafo, 65, 3 de fevereiro.

s.a. 1942c. "Do Brasil a Portugal”. Diário de Notícias, 7 de janeiro.

Almeida, Avelino. 1932. "O êxito da subscrição pública". Cinéfilo, 199, 11 de junho.

Antunes, João e Matos-Cruz, José de. 1997. Cinema Português 18961998. Lisboa: Lusomundo.

Costa, Hamílcar. 1933. “H. da Costa fala...”. Movimento, 6, 15 de setembro.

Costa, João Bénard da. 1991. Histórias do Cinema. Lisboa: Imprensa Nacional Casa da Moeda.

-_- 1996. O Cinema Português Nunca Existiu. Lisboa: CTT Correios de Portugal.

Cunha, Paulo. 2010. "As narrativas históricas no cinema português durante o Estado Novo (1932-74)". O Olho da História, 14: 112. http://oolhodahistoria.org/n14/artigos/paulo.pdf. Acedido em 10 de junho de 2013.

Fraga, Augusto. 1939. "A propósito da última "tabela de serviço" da Varanda dos Rouxinóis”. Cinéfilo, 574, 18 de agosto.

Ferro, António. 1931. Hollywood, Capital das Imagens, 2a ed. Lisboa: Portugal-Brasil.

-_- 1933. Salazar, o Homem e a sua Obra. Lisboa: Empresa Nacional de Publicidade.

———. 1935. A Política do Espírito e os Prémios Literários do S.P.N. Lisboa: SPN.

_-_. 1941. "Um discurso e uma verdade". Animatógrafo, 25, 28 de abril.

-_-. 1949a. Arte Moderna. Lisboa: SNI.

__—. 1949b. Estados Unidos da Saudade. Lisboa: SNI.

-_- 1950. Teatro e Cinema (1936-1949). Lisboa: SNI.

Folgar de la Calle, José Maria. 2006. "Sobre Inés de Castro y Reina Santa, Películas Hispanoportuguesas de los años 40". Porta da aira: revista de historia delarteorensano, 11: 547-561. http://dialnet.unirioja.es/servlet/articulo? codigo $=2483047$. Acedido em 27 de julho de 2013.

Gaspar, José da Natividade. 1934.“Gado Bravo”. Cinéfilo, 313, 18 de agosto.

Lopes, Norberto. 1930."Uma vez organizada a indústria cinematográfica portuguesa, criemos um cinema português!”. Kino, 16, 14 de agosto. 
Melo, Daniel. 2001. Salazarismo e Cultura Popular (1933-1958). Lisboa: ICS.

Minguet i Batllori, Joan M. 2000. La regeneración del cine como hecho cultural durante el primer franquismo (Manuel Augusto García Viñolas y la etapa inicial de "Primer Plano"). Alicante: Biblioteca Virtual Miguel de Cervantes.

http://www.cervantesvirtual.com/obra-visor/laregeneracion-del-cine-como-hecho-cultural-durante-elprimer-franquismo-manuel-augusto-garcia-vinolas-y-la-etapainicial-de-primer-plano--0/html/ff8c69ea-82b1-11df-acc7002185ce6064_2.html\#I_1_ Acedido em 27 de julho de 2013.

Ó, Jorge Ramos do. 1996. "Secretariado de Propaganda Nacional (SPN) /Secretariado Nacional de Informação, Cultura Popular e Turismo (SNI) /Secretaria de Estado da Informação e Turismo (SEIT)." In Dicionário de História do Estado Novo, dirigido por Fernando Rosas e J. M. Brandão de Brito, vol. II, 893-896. Lisboa: Círculo de Leitores.

- - . 1999. Os anos de Ferro - o dispositivo cultural durante a "Política de Espírito" (1933-1949): ideologia, instituições, agentes e práticas. Lisboa: Editorial Estampa.

Paulo, Heloísa. 2001.“A colónia portuguesa do Brasil e o cinema no Estado Novo. Meios e limites de um veículo de propaganda” In O cinema sob o olhar de Salazar, coordenado por Luís Reis Torgal, 117-136. Lisboa: Temas e Debates.

Pereira, Herculano. 1933. "Um caso sério de organização". Imagem, 83, 12 de junho.

Piçarra, Maria do Carmo. 2006. Salazar vai ao cinema. O Jornal Português de Actualidades Filmadas. Coimbra: Edições Minerva.

Pina, Luís de. 1986. História do Cinema Português. Mem-Martins: Publicações Europa-América.

Pinto, Armando Vieira. 1933. “Cinema português”. Movimento, 12, 15 de dezembro.

Rebelo, José. 1998. Formas de legitimação do poder no Salazarismo. Lisboa: Livros e Leitura.

Ribeiro, António Lopes.1933. "Filmes internacionais”. Animatógrafo, 12, 22 de junho.

-_-1934. "O Cinema visto ao pé”. Movimento, 14, 15 de Janeiro.

———. 1941. "Artigos de primeira necessidade". Animatógrafo, 32, 16 de junho.

Ribeiro, M. Félix. 1983. Filmes, figuras e factos da história do cinema português (1896-1949). Lisboa: Cinemateca Portuguesa. 
Rosas, Fernando. 2001. "O Salazarismo e o homem novo: ensaio sobre o Estado Novo e a questão do totalitarismo". Análise Social, XXXV (157): 1031-1054.

Torgal, Luís Reis. 2001. "Cinema, estética e ideologia no Estado Novo”. Estudos do Século XX, 1: 157-202.

- - - 2012. Estados Novos, Estado Novo, $2^{\text {a }}$ ed., 2 vols. Coimbra: Imprensa da Universidade de Coimbra.

Recebido em 19-6-2013. Aceite para publicação em 11-2-2014. 